\title{
End-tidal concentration of sevoflurane for reducing rocuronium-induced withdrawal reactions in adult patients: a comparison between male and female patients
}

\author{
Jong Hoon Yeom, Kyoung Hun Kim, Gyu Ho Choe, and Jae Min Lee \\ Department of Anesthesiology and Pain Medicine, Hanyang University Guri Hospital, Hanyang University College of Medicine, \\ Guri, Korea
}

Background: In this study, we assessed the $50 \%$ effective concentration $\left(\mathrm{EC}_{50}\right)$ of sevoflurane for reducing a rocuroniuminduced reaction, based on the Dixon's up-and-down method. We also assessed the 50 and $95 \%$ effective end-tidal concentration of sevoflurane (ETsev), based on the probit regression curve of the probability of nonwithdrawal reaction.

Methods: We conducted a prospective, double-blind study in 23 males and 24 females. After using 2.5\% thiopental sodium $(4 \mathrm{mg} / \mathrm{kg})$, anesthesia was induced in the patients. The patients then inhaled sevoflurane with $5 \mathrm{vol} \%$ in $6 \mathrm{~L} / \mathrm{min}$ of oxygen. When the target ETsev was achieved, a nurse injected the intubating dose of rocuronium $(0.6 \mathrm{mg} / \mathrm{kg})$ for 5-10 s under the free flow of intravenous fluid. After the nurse evaluated the response, the nurse recorded the maximum heart rate during $30 \mathrm{~s}$ and the mean arterial pressure after rocuronium injection.

Results: Based on Dixon's up-and-down method, the $\mathrm{EC}_{50}$ of sevoflurane was $2.5 \pm 0.5 \mathrm{vol} \%$ in males and $2.5 \pm 0.3$ vol\% in females. The probit regression curve of the probability of nonwithdrawal reaction showed that in males the $50 \%$ effective ETsev was 2.4 vol\% (95\% confidence interval [CI], 1.5-3.1 vol\%) and the 95\% effective ETsev was 3.5 vol\% (95\% CI, 2.9-11.0 vol\%); in females, the 50\% effective ETsev was 2.4 vol\% (95\% CI, 2.1-2.7 vol\%) and the 95\% effective ETsev was 3.0 vol\% (95\% CI, 2.7-4.5 vol\%).

Conclusions: The inhalation of sevoflurane during the induction period may provide a simple and reliable means of reducing rocuronium-induced reactions without adverse hemodynamic changes. There was no significant difference between males and females. (Korean J Anesthesiol 2014; 66: 439-443)

Key Words: Rocuronium, Sevoflurane, Withdrawal.

\footnotetext{
Received: November 1, 2013. Revised: December 6, 2013. Accepted: December 7, 2013.

Corresponding author: Jong Hoon Yeom, M.D., Department of Anesthesiology and Pain Medicine, Hanyang University Guri Hospital, 153, Gyeongchun-ro, Guri 471-701, Korea. Tel: 82-31-560-2390, Fax: 82-31-563-1731, E-mail: yeomjh@hanyang.ac.kr

(c) This is an open-access article distributed under the terms of the Creative Commons Attribution Non-Commercial License (http:// creativecommons.org/licenses/by-nc/3.0/), which permits unrestricted non-commercial use, distribution, and reproduction in any medium, provided the original work is properly cited.
} 


\section{Introduction}

Many rocuronium-induced reactions have been reported. Sudden withdrawal movement and pain during the rocuronium injection may cause injury, an inadequate injection of rocuronium, or sympathetic stimulation. Several pretreatments and techniques have been attempted to blunt or abolish these reactions; however, the treatments do not completely prevent the reactions. Popular methods involve pretreatment with various drugs. We hypothesized that the inhalation of volatile anesthetics during intravenous (IV) induction and the maintenance of an adequate anesthetic depth could reduce rocuronium-induced reactions. In one study, inhalation induction with sevoflurane in children reduced rocuronium-induced withdrawal movement [1]. However, no previous study has reported the end-tidal concentration of sevoflurane (ETsev) in adults that is needed to reduce arm withdrawal associated with the intubating dose of rocuronium $(0.6 \mathrm{mg} / \mathrm{kg})$ during thiopental sodium induction. In addition, the incidence and the degree of withdrawal reactions were significantly higher in female adult patients than in male adult patients $[2,3]$.

This purpose of this study was to assess the $50 \%$ effective concentration $\left(\mathrm{EC}_{50}\right)$ of sevoflurane for reducing rocuroniuminduced reaction, based on the Dixon's up-and-down method, and to assess the 50 and 95\% effective ETsev, based on the probit regression curve of the probability of nonwithdrawal reaction in male and female adult patients.

\section{Materials and Methods}

This study was approved by the Institutional Review Board of our hospital. All patients provided written, informed consent. We studied 47 adult patients who were at the American Society of Anesthesiologists physical status I or II and who were undergoing general anesthesia for elective surgery. We excluded patients who had a history of neurological deficits; allergies to thiopental or rocuronium; asthma; a body weight greater than $20 \%$ of the ideal body weight; an anticipated difficult ventilation; and patients who had received analgesics or sedatives within the previous $24 \mathrm{~h}$.

Patients were allocated to 2 groups, according to their gender (i.e., male group and female group). Premedication was not administered before the induction of anesthesia. Before arriving in the operating room, we required that a 20 -gauge IV cannula be placed in the patient's largest vein on the dorsum of the hand in the ward. Ringer's lactate solution was chosen for the IV fluid. All patients were monitored by electrocardiography and pulse oximetry, and for automatic noninvasive blood pressure, end-tidal concentration of $\mathrm{CO}_{2}\left(\mathrm{ETCO}_{2}\right)$, and ETsev (Dräger; Drägerwerk AG and Co., Lübeck, Germany).
After the free flow of IV fluid was confirmed by gravity, the patient underwent anesthesia induction with $2.5 \%$ thiopental sodium ( $4 \mathrm{mg} / \mathrm{kg})$. After confirming that the patient experienced loss of the eyelash reflex, the patient inhaled sevoflurane with 5 vol\% in $6 \mathrm{~L} / \mathrm{min}$ of oxygen. The heart rate $(\mathrm{HR})$ and the mean arterial pressure (MAP) were recorded. Manual ventilation was adjusted to maintain the $\mathrm{ETCO}_{2}$ between $25 \mathrm{mmHg}$ and 30 mmHg. When the target ETsev was attained, a nurse (who was blinded to ETsev) injected the intubating dose of rocuronium $(0.6 \mathrm{mg} / \mathrm{kg})$ for $5-10 \mathrm{~s}$ under the free flow of the IV fluid. After the response was evaluated by the nurse, the maximum HR for $30 \mathrm{~s}$ and the MAP after the rocuronium injection were recorded. The study was terminated at this point, and the anesthetic was continued at the discretion of the attending anesthesiologist.

Patient data are presented as the mean \pm standard deviation (SD). We studied 23 male patients and 24 female patients, utilizing Dixon's up-and-down method. Every eight pairs of withdrawal and nonwithdrawal movements were collected for statistical analysis by this method [4]. The $\mathrm{EC}_{50}$ based on the Dixon's up-and-down method was defined as the mean of the crossover end-tidal concentration. The withdrawal movement sequences and nonwithdrawal movement sequences were each analyzed by the probit test, which enabled us to derive the ETsev for the nonwithdrawal movement with $95 \%$ confidence limits of the mean. The male and female patients' characteristics (i.e., a comparison between the patients in each group with withdrawal movement and nonwithdrawal movement at the rocuronium injection, and a comparison of the $\mathrm{EC}_{50}$ between the groups) were performed by using chi-square analysis and the Mann-Whitney $\mathrm{U}$ test, when appropriate. The MAP and HR before and after the rocuronium injection in the withdrawal patient group and the nonwithdrawal movement patient group were compared by the Wilcoxon signed-rank test. The differences in the MAP and HR before and after the rocuronium injection between the withdrawal patient group and the nonwithdrawal movement patient group were analyzed by the Mann-Whitney $U$ test because of the non-normal distribution and small sample size. The differences were considered statistically significant when $\mathrm{P}<0.05$. Statistical analysis was performed by SPSS package software, version 19.0 (SPSS Inc., Chicago, IL, USA).

\section{Results}

The data were collected from 23 male and 24 female adult patients. Fig. 1 show the sequences of withdrawal and nonwithdrawal reactions in the male and female groups, respectively. In the male group, nonwithdrawal reactions were observed in 4 of 5 patients with ETsev 3.0 vol\% and in 5 of 9 patients with ETsev 2.5 vol\%. Based on the Dixon's up-and-down method, the $\mathrm{EC}_{50}$ of sevoflurane for a nonwithdrawal reaction with the 
A

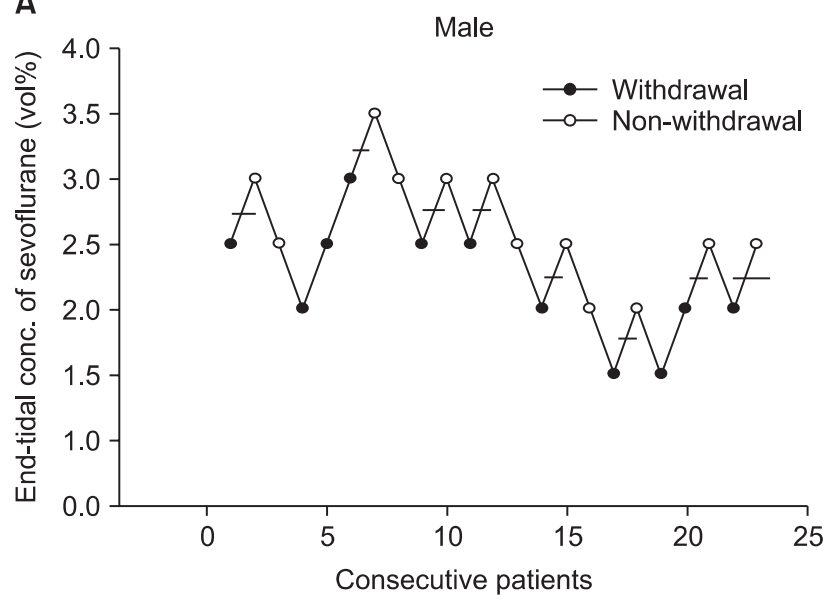

B

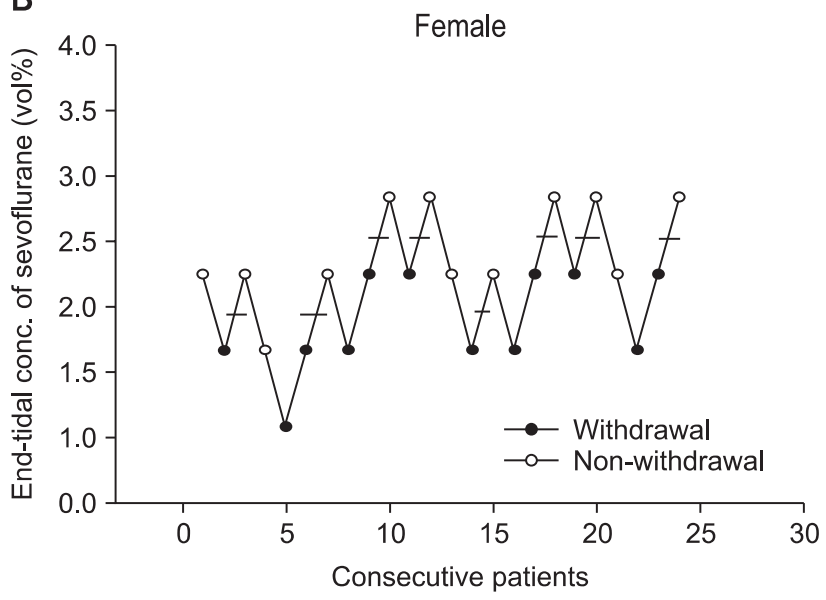

Fig. 1. (A) Data of consecutive withdrawal and nonwithdrawal movement for the predetermined end-tidal concentration of sevoflurane in males (with an initial predetermined concentration of $2.5 \mathrm{vol} \%$ for the first patient). We collected eight pairs of withdrawal and nonwithdrawal movement sequences for statistical analysis using the Dixon's up-and-down method. The end-tidal concentration of sevoflurane for abolishing withdrawal movement was $2.5 \pm 0.5 \mathrm{vol} \%$ in $50 \%$ of patients. (B) The data of consecutive withdrawal and nonwithdrawal movement during a predetermined endtidal concentration of sevoflurane in females (with an initial predetermined concentration of $2.5 \mathrm{vol} \%$ for the first patient). We collected eight pairs of withdrawal and nonwithdrawal movement sequences for statistical analysis using Dixon's up-and-down method. The end-tidal concentration of sevoflurane for abolishing withdrawal movement was $2.5 \pm 0.3 \mathrm{vol} \%$ in $50 \%$ of patients.

Table 1. Male Profiles

\begin{tabular}{lcc}
\hline & Withdrawal & Nonwithdrawal \\
\hline Number of patients & 11 & 12 \\
ASA (physical status I/II) & $6 / 6$ & $7 / 5$ \\
Age (yr) & $39.7 \pm 8.9$ & $44.6 \pm 14.3$ \\
Body weight (kg) & $70.3 \pm 8.9$ & $67.3 \pm 6.3$ \\
Height (cm) & $172.6 \pm 4.0$ & $169.9 \pm 4.8$ \\
ETsev at the rocuronium injection* & $2.2 \pm 0.5$ & $2.7 \pm 0.4$ \\
\hline
\end{tabular}

The profiles of patients with withdrawal movement and nonwithdrawal movement at the rocuronium injection. The values are expressed as the mean \pm the standard deviation or by the number. ASA: American Society of Anesthesiologists, ETsev: end-tidal concentration of sevoflurane. $* \mathrm{P}=0.024$, compared between the withdrawal and nonwithdrawal movement patients.

rocuronium injection was $2.5 \pm 0.5 \mathrm{vol} \%$ in the male group. The probit regression curve of the probability of the nonwithdrawal reaction showed that the $50 \%$ effective ETsev for abolishing the withdrawal reaction during rocuronium injection was 2.4 vol\% (95\% confidence interval [CI], 1.5-3.1 vol\%), and the 95\% effective ETsev was 3.5 vol\% (95\% CI, 2.9-11.0 vol\%). In the female group, the nonwithdrawal reaction was observed in 5 of 5 patients with ETsev $3.0 \mathrm{vol} \%$ and in 6 of 11 patients with ETsev $2.5 \mathrm{vol} \%$. Based on the Dixon's up-and-down method, the $\mathrm{EC}_{50}$ of sevoflurane in the female group was $2.5 \pm 0.3 \mathrm{vol} \%$. The probit regression curve of the probability of nonwithdrawal reaction showed that the $50 \%$ effective ETsev for abolishing the withdrawal reaction with the rocuronium injection was $2.4 \mathrm{vol} \%$ (95\% CI, 2.1-2.7 vol\%) and the $95 \%$ effective ETsev was 3.0 vol\% (95\% CI, $2.7-4.5$ vol\%).
Table 2. Female Profiles

\begin{tabular}{lcc}
\hline & Withdrawal & Nonwithdrawal \\
\hline Number of patients & 12 & 12 \\
ASA (physical status I/II) & $6 / 6$ & $5 / 7$ \\
Age (yr) & $45.1 \pm 8.8$ & $49.0 \pm 10.7$ \\
Body weight $(\mathrm{kg})$ & $55.7 \pm 7.0$ & $56.3 \pm 6.5$ \\
Height (cm) & $156.9 \pm 5.7$ & $157.3 \pm 8.1$ \\
ETsev at the rocuronium injection* & $2.2 \pm 0.3$ & $2.7 \pm 0.3$ \\
\hline
\end{tabular}

The profiles of patients with withdrawal movement and nonwithdrawal movement with the rocuronium injection. The values are expressed as the mean \pm standard deviation or number. ASA: American Society of Anesthesiologists, ETsev: end-tidal concentration of sevoflurane. $* \mathrm{P}=0.002$, compared between withdrawal movement and nonwithdrawal movement patients.

There was no significant difference between the male and female groups in the $\mathrm{EC}_{50}$ of sevoflurane, based on the Dixon's up-and-down method. During the study, hemodynamic stability within $30 \%$ of the preoperative values was maintained in all patients.

The patient profiles of the male and the female groups are compared in Tables 1 and 2 with regard to withdrawal movement and nonwithdrawal movement. The hemodynamic values of patients with withdrawal movement and nonwithdrawal movement are compared in Tables 3 and 4. The HR in the male and female patients with withdrawal movement was significantly higher after the rocuronium injection $(P=0.003)$ than before the rocuronium injection $(\mathrm{P}=0.004)$, but was not significantly different between the male and female patients with nonwithdrawal movement. The differences in MAP were not statistically 
Table 3. Male Hemodynamic Profiles

\begin{tabular}{llll}
\hline & & $\begin{array}{c}\text { Withdrawal } \\
(\mathrm{n}=11)\end{array}$ & $\begin{array}{c}\text { Nonwithdrawal } \\
(\mathrm{n}=12)\end{array}$ \\
\hline HR (beats/min) & T1 & $75.5 \pm 17.1^{*}$ & $75.7 \pm 8.5$ \\
& T2 & $90.2 \pm 16.0$ & $89.4 \pm 13.3$ \\
MAP (mmHg) & T1 & $89.8 \pm 5.6$ & $94.8 \pm 18.5$ \\
& T2 & $90.5 \pm 7.7$ & $88.5 \pm 17.2$ \\
\hline
\end{tabular}

Hemodynamic profiles before and after rocuronium injection in the withdrawal and nonwithdrawal movement patients. The values are expressed as the mean \pm standard deviation. HR: heart rate, MAP: mean arterial pressure, T1: time before rocuronium injection, T2: time after rocuronium injection. ${ }^{*} \mathrm{P}=0.003$, compared between $\mathrm{T} 1$ and $\mathrm{T} 2$.

significant between patients in the male group and the female group with withdrawal movement and nonwithdrawal movement.

\section{Discussion}

Withdrawal reactions in response to the injection of rocuronium were not associated with adverse clinical consequences for the patient's outcome. No patient remembered any pain or withdrawal reaction with the rocuronium injection in the induction period. A withdrawal reaction may result in dislodgement of the venous catheter or an inadequate injection of rocuronium, and rocuronium-induced pain may cause bronchospasm, asthma, or myocardial ischemia attack [5]. While many theories have been suggested, the exact mechanism of rocuroniuminduced reactions is not yet elucidated [6-10].

Up to $80 \%$ of awake patients or volunteers have reactions with a subparalysing dose of rocuronium [10]. When rocuronium is used for neuromuscular blockade, withdrawal reactions were lower than in the awake patients [11]. However, in another study, pediatric patients had an $83 \%$ incidence of rocuroniuminduced withdrawal reactions during thiopental sodium induction [7]. The overall incidence of withdrawal reactions and the incidence of severe reactions with the rocuronium injection were significantly higher in female patients than in male patients during the induction of anesthesia $[2,3]$. In addition, women exhibit greater pain sensitivity to a rocuronium injection administered in the luteal phase than in the follicular phase of their menstrual cycle [12]. However, we did not investigate informa-
Table 4. Female Hemodynamic Profiles

\begin{tabular}{lccc}
\hline & & $\begin{array}{c}\text { Withdrawal } \\
(\mathrm{n}=12)\end{array}$ & $\begin{array}{c}\text { Nonwithdrawal } \\
(\mathrm{n}=12)\end{array}$ \\
\hline HR (beats/min) & T1 & $89.5 \pm 16.0^{*}$ & $87.0 \pm 11.5$ \\
& T2 & $99.9 \pm 21.4$ & $92.1 \pm 13.0$ \\
MAP (mmHg) & T1 & $86.0 \pm 10.6$ & $91.3 \pm 12.6$ \\
& T2 & $85.9 \pm 11.4$ & $89.4 \pm 14.4$ \\
\hline
\end{tabular}

Hemodynamic profiles before and after the rocuronium injection in the withdrawal and nonwithdrawal movement patients. The values are expressed as the mean \pm standard deviation. HR: heart rate, MAP: mean arterial pressure, T1: time before rocuronium injection, T2: time after rocuronium injection. $* \mathrm{P}=0.004$, compared between $\mathrm{T} 1$ and $\mathrm{T} 2$.

tion about the menstrual cycle.

Various pretreatments with several drugs, nitrous oxide, or a combination of agents, and various techniques to prevent rocuronium-induced withdrawal movement have been suggested with varying success (30-96\%); they have not completely eliminated the movement $[3,7,13-20]$. However, these techniques require cumbersome and/or time-consuming procedures, and may have side effects or contraindications.

In this study, we used sevoflurane with the goal of determining the ETsev necessary to eliminate arm withdrawal movement with rocuronium injection in male and female patients during thiopental induction. Based on the Dixon's up-and-down method, the $\mathrm{EC}_{50}$ of sevoflurane for the nonwithdrawal reaction with the rocuronium injection was $2.5 \pm 0.5 \mathrm{vol} \%$ in the male group and $2.5 \pm 0.3$ vol\% in the female group. There was no significant difference between the male and female groups. On the basis of the probit regression curve of the probability of nonwithdrawal reaction, the $95 \%$ effective concentrations were $3.5 \mathrm{vol} \%$ in the male group and $3.0 \mathrm{vol} \%$ in the female group.

In conclusion, the inhalation of sevoflurane during the induction period may provide a simple and reliable means of reducing rocuronium-induced reactions without adverse hemodynamic changes. The incidence and the degree of withdrawal reactions were significantly higher in the female patients than in the male patients, although the $95 \%$ effective concentrations of sevoflurane for the nonwithdrawal reaction with the rocuronium injection were $3.5 \mathrm{vol} \%$ in the male group and $3.0 \mathrm{vol} \%$ in the female group during thiopental sodium induction.

\section{References}

1. Park SH, Oh AY, Goo EK, Nahm FS, Min SW, Hwang JW, et al. A short period of inhalation induction with sevoflurane prevents rocuronium-induced withdrawal in children. Acta Anaesthesiol Scand 2011; 55: 87-91.

2. Mencke T, Beerhalter U, Fuchs-Buder T. Spontaneous movements, local reactions and pain on injection of rocuronium. A comparison between female and male patients. Acta Anaesthesiol Scand 2001; 45: 1002-5. 
3. Kim KS, Kim YS, Jeon WJ, Yeom JH. Prevention of withdrawal associated with the injection of rocuronium in adults and children. J Clin Anesth 2006; 18: 334-8.

4. Dixon WJ. Staircase bioassay: the up-and-down method. Neurosci Biobehav Rev 1991; 15: 47-50.

5. Morishima T, Sobue K, Arima H, Tanaka S, So M, Ando H, et al. Profound pain due to propofol injection triggered myocardial ischemia in a patient with a suspected pheochromocytoma. Anesth Analg 2003; 96: 631.

6. Klement W, Arndt JO. Pain on i.v. injection of some anaesthetic agents is evoked by the unphysiological osmolality or $\mathrm{pH}$ of their formulations. Br J Anaesth 1991; 66: 189-95.

7. Liou JT, Hsu JC, Liu FC, Ching-Wah Sum D, Lui PW. Pretreatment with small-dose ketamine reduces withdrawal movements associated with injection of rocuronium in pediatric patients. Anesth Analg 2003; 97: 1294-7.

8. Kindgen-Milles D, Klement W, Arndt JO. The nociceptive systems of skin, paravascular tissue and hand veins of humans and their sensitivity to bradykinin. Neurosci Lett 1994; 181: 39-42.

9. Blunk JA, Seifert F, Schmelz M, Reeh PW, Koppert W. Injection pain of rocuronium and vecuronium is evoked by direct activation of nociceptive nerve endings. Eur J Anaesthesiol 2003; 20: 245-53.

10. Borgeat A, Kwiatkowski D. Spontaneous movements associated with rocuronium: is pain on injection the cause? Br J Anaesth 1997; 79: $382-$ 3.

11. Feldman SA. Rocuronium - onset times and intubating conditions. Eur J Anaesthesiol Suppl 1994; 9: 49-52.

12. Honca M, Purtuloglu T, Honca T, Sizlan A, Deniz S, Kose A, et al. Effects of the menstrual cycle on injection pain due to rocuronium. J Clin Anesth 2013; 25: 399-402.

13. Memiş D, Turan A, Karamanlioğlu B, Süt N, Pamukçu Z. The prevention of pain from injection of rocuronium by ondansetron, lidocaine, tramadol, and fentanyl. Anesth Analg 2002; 94: 1517-20.

14. Kim JY, Kim JY, Kim YB, Kwak HJ. Pretreatment with remifentanil to prevent withdrawal after rocuronium in children. Br J Anaesth 2007; 98: 120-3.

15. Jeon YH, Ha JH, Lee JE, Lee HC, Ryu T, Kwak KH. Rocuronium-induced withdrawal movement: influence of ketorolac or a combination of lidocaine and ketorolac pretreatment. Korean J Anesthesiol 2013; 64: 25-8.

16. Kwak HJ, Chae YJ, Lee SY, Kim YJ, Kim JY. Combination of nitrous oxide and lidocaine to prevent withdrawal after rocuronium in children. Korean J Anesthesiol 2010; 58: 446-9.

17. Sharma S, Sharma D, Jain A, Jain A. Effect of nitrous oxide on pain due to rocuronium injection: A randomised, double-blind, controlled clinical trial. Indian J Anaesth 2010; 54: 142-6.

18. Yavascaoglu B, Kaya FN, Ozcan B. Esmolol pretreatment reduces the frequency and severity of pain on injection of rocuronium. J Clin Anesth 2007; 19: 413-7.

19. Jeon Y, Baek SU, Park SS, Kim SO, Baek WY, Yeo JS. Effect of pretreatment with acetaminophen on withdrawal movements associated with injection of rocuronium: a prospective, randomized, double-blind, placebo controlled study. Korean J Anesthesiol 2010; 59: 13-6.

20. Yoon JS, Jeon HJ, Cho SS, Lee JD, Kang KO, Ryu SW, et al. Effect of pretreatment with gabapentin on withdrawal movement associated with intravenous rocuronium injection. Korean J Anesthesiol 2011; 61: 367-71. 